\title{
Cell Therapy for Knee Osteoarthritis: Mesenchymal Stromal Cells
}

\author{
Christopher Kim ${ }^{\mathrm{a}} \quad$ Armand Keating ${ }^{\mathrm{a}, \mathrm{b}}$ \\ ${ }^{a}$ Krembil Research Institute, Toronto Western Hospital, Toronto, ON, Canada; ${ }^{b}$ Cell Therapy Translational Research \\ Laboratory, Princess Margaret Cancer Centre, Toronto, ON, Canada
}

\section{Keywords}

Mesenchymal stromal cells · Aging · Osteoarthritis

\begin{abstract}
Osteoarthritis (OA) is designated the 11th highest contributor of 291 diseases of global disability and the most common cause of chronic disability in elderly people. OA has a devastating impact on quality of life and represents an enormous socio-economic burden. Currently, OA is incurable, and no approved medications, biological therapy, or procedure prevents the progressive destruction of the osteoarthritic knee joint. All current treatments provide symptomatic relief rather than preventative or regenerative results. There is an urgent and compelling need to find, validate, and test new biological therapeutics. Cell-based therapies involving the delivery of mesenchymal stromal cells (MSCs) to the osteoarthritic knee joint have emerged as a potential solution to overcome this clinical shortcoming. In this review, we address the clinical evidence, challenges, and recent advances surrounding MSC treatment in knee OA.
\end{abstract}

C 2019 S. Karger AG, Basel

\section{Introduction}

Osteoarthritis (OA) of the knee is a chronic, degenerative, whole-joint disease characterized by degradation and loss of articular cartilage, osteophyte formation, subchondral bone remodelling, and inflammation of the synovial membrane [1]. A dysregulation of chondrocyte homeostasis results in the progressive degradation of cartilage extracellular matrix and this catabolic process involves pro-inflammatory cytokines and matrix metalloproteinases [1]. People living with knee OA complain of joint pain, loss of joint function, reduced mobility, and decreased quality of life [2].

Currently, knee OA is managed using non-surgical treatments such as weight loss, physiotherapy, bracing, and medications, including acetaminophen, non-steroidal anti-inflammatory drugs (NSAIDs), opioids, and intra-articular (IA) knee injections, including corticosteroids, hyaluronic acid (HA), platelet-rich plasma (PRP), and mesenchymal stromal cells (MSCs; Box 1). Cyclooxygenase-2 (COX-2) inhibitor use is associated with adverse side effects, including gastrointestinal complications and increased risk of myocardial infarction [3]. Although effective in the short-term, multiple corticosteroid injections in a joint and prolonged exposure to steroids can

\section{KARGER}

(c) 2019 S. Karger AG, Basel

E-Mail karger@karger.com

www.karger.com/ger
Christopher Kim

Toronto Western Hospital

Room 1 East 449, 399 Bathurst Street

Toronto, ON M5T 2S8 (Canada)

E-Mail ck.kim@mail.utoronto.ca 
Box 1. Main IA injections for knee OA

$$
\begin{aligned}
& \text { - Corticosteroids } \\
& \text { - Hyaluronic acids } \\
& \text { - Platelet-rich plasma } \\
& \text { - Autologous mesenchymal stromal cells }
\end{aligned}
$$

harm articular cartilage and accelerate progression of $\mathrm{OA}$ [4]. In a recent systematic review of overlapping metaanalyses comparing treatment of knee OA with IA HA versus oral NSAIDs, IA injection of corticosteroids, PRP, or placebo, Campbell et al. [5] reported no differences in knee pain and function between HA versus NSAIDs, greater effects of PRP versus HA, and positive effects of HA versus corticosteroids and placebo, with HA providing knee pain relief for 26 weeks compared to corticosteroids. In another systematic review of overlapping metaanalyses, the same authors compared treatment of knee OA with IA PRP versus oral NSAIDs, IA injection of corticosteroids, HA, or placebo [6]. The authors showed that IA injection of PRP significantly improved patient knee pain and function through 6-12 months compared with IA HA or placebo [6]. Most recently, Jevsevar et al. [7] designed a network meta-analysis comparing nonsurgical treatments for knee $\mathrm{OA}$ that included acetaminophen, NSAIDs, IA corticosteroids, IA HA, IA PRP, IA placebo, and oral placebo. The cumulative probabilities supported naproxen as the most probable to improve patient knee pain and function, followed by IA corticosteroids, IA PRP, celecoxib, and ibuprofen [7]. When these non-surgical treatments fail, total knee arthroplasty (TKA) is the only remaining option for end-stage knee OA. TKA remains the gold standard for end-stage knee OA, is the most effective intervention for severe OA, and is becoming increasingly relied upon to reduce pain, disability, and restore some patients to near normal function [8]. Despite its effectiveness, TKA is often associated with complications, such as infection, incorrect implant position, instability, postoperative stiffness, and pain which causes increased morbidity and decreased patient satisfaction [8]. The risk of failure of a TKA needing revision surgery 10 years postoperatively is $5 \%$ [9]. Pooled data from national joint registries worldwide reported that the most common indications for revision TKA included aseptic loosening (29.8\%), infection (14.8\%), and pain (9.5\%) [10-13]. Other main indications for revision TKA were patellofemoral pain, instability, and stiffness [9]. Unfortunately, the demand for TKA is expected to rise as the baby boomer gen- eration ages and younger and active patients increasingly request TKA [14]. Therefore, a novel regenerative medicine strategy for knee OA is necessary.

The direct injection of MSCs into an osteoarthritic joint may enhance the normally limited repair and reduce destructive processes. The regenerative capacity of MSCs was established using preclinical OA animal models. In a collagenase-induced OA mouse model, $20 \times 10^{3}$ mouse adipose-derived MSCs (ASCs) were injected intra-articularly into mouse knee joints 7 days after induction [15]. Forty-two days after ASC injection, the ASC-treated mice showed decreased synovial thickening, reduced formation of enthesophytes, and inhibited cartilage destruction compared to control-treated mice [15]. In an anterior cruciate ligament transection (ACLT) OA rabbit model, Desando et al. [16] injected $2 \times 10^{6}$ and $6 \times 10^{6}$ rabbit ASCs into the knee 8 weeks after ACLT. At 16 and 24 weeks after cell injection, the $2 \times 10^{6}$ ASC-treated groups showed a significant decrease of Laverty's score and reduced expression of tumour necrosis factor- $\alpha$ and matrix metalloproteinase-1 compared to controls [16]. In a closed tibial plateau fracture mouse model of post-traumatic OA, Diekman et al. [17] injected $10 \times 10^{3}$ mouse C57BL/6-derived or MRL/MpJ-derived MSCs into mouse knee joints immediately after fracture. At 8 weeks after injection, the MSC-treated groups demonstrated significantly reduced modified Mankin OA scores, altered levels of synovial interleukin- $1 \beta$ and serum IL-10, and increased bone volume compared to control knees [17]. Therefore, a promising regenerative medicine therapy may be the IA injection of MSCs into osteoarthritic knees.

\section{OA in Older Adults}

The prevalence of OA considerably increases with age $[18,19]$. It is estimated that $30-50 \%$ of adults 65 years and over suffer from $\mathrm{OA}$ and present with significant pain or disability $[18,19]$. Greater than $80 \%$ of adults over the age of 55 years have at least one joint, either hand, spine, hip, or knee, showing radiographic changes of OA [20].

Age is one of the common risk factors for the development of OA [21]. Other common risk factors include obesity, sex, history of joint injury, race, genetics, anatomical and nutritional factors [21,22]. Age-related factors that contribute to the development of OA include oxidative stress and damage [23], muscle weakness [24], decreased proprioception [25], damage to meniscus and ligaments $[26,27]$, thinning of articular cartilage [28], increased subchondral bone remodelling [29], and calcium crystal 
deposition within joint tissue [30]. Age-related changes in cells and tissues may alter joint homeostasis leading to an insufficient response to joint stress and injury, and cause cartilage and surrounding joint tissue damage and loss. Therefore, the use of MSCs may alter the destructive age-related changes to the joint by augmenting the normally limited repair, limit degenerative changes, replace lost or damaged cells and tissues, and reduce inflammatory mediators.

\section{MSCs for OA}

MSCs are multipotent progenitors derived from nonhematopoietic adult stem cell populations present in numerous tissues, including bone marrow, peripheral blood, adipose tissue, synovium, placenta, and umbilical cord [31]. According to the International Society for Cellular Therapy, human MSCs are defined as plastic adherent, positive for CD105, CD73, and CD90 markers, negative for CD45, CD34, CD14 or CD11b, CD79 $a$ or CD19, and HLA-DR, and able to differentiate into osteoblasts, chondroblasts, and adipocytes [32]. In addition, MSCs possess intrinsic immunomodulatory properties and can reduce inflammation and support other cells, thereby enhancing angiogenesis, cell survival and differentiation, and preventing fibrosis [33].

Currently, primary isolated stromal cells represent the best option for treatment of OA. The most common sources of MSCs for clinical use are bone marrow-derived stromal cells (BMSCs) and ASCs. BMSCs are commonly harvested from the posterior superior iliac spine as bone marrow concentrate, which contain MSCs, hematopoietic stem cells, endothelial progenitor cells, and associated cytokine and growth factors [34]. ASCs are isolated from the stromal vascular fraction of homogenized adipose tissue generally harvested from subcutaneous sites and the infrapatellar fat pads [34]. In comparison to BMSCs, ASCs have greater cell yield, proliferative capacity in culture, and differentiation potential $[35,36]$. However, there are no clinical trials comparing BMSCs and ASCs in knee OA [34].

\section{Bone Marrow-Derived MSCs}

In a small clinical study, Orozco et al. [37] studied the clinical efficacy and safety of direct IA injection of $40 \times$ $10^{6}$ autologous human BMSCs in 12 patients with knee OA. The BMSC-injected patients reported decreased knee pain, no serious adverse effects, and improved articular cartilage quality on post-treatment MRI scans of the knee [37]. In a double-blinded, randomized controlled trial (RCT), Vangsness et al. [38] investigated the effect and safety of IA injection of allogeneic human BMSCs in human OA knees following partial medial meniscectomy. In the 18 patients who received $50 \times 10^{6}$ BMSCs and another group of 18 patients who received $150 \times 10^{6} \mathrm{BMSCs}$, there was evidence of meniscus regeneration and significant reduction in knee pain compared to control patients who did not receive an injection [38]. In another study, Vega et al. [39] randomized 30 patients with knee OA into 2 groups with 15 patients receiving IA injections of $40 \times 10^{6}$ allogeneic human BMSCs and 15 patients in the control group receiving IA injections of HA. The BMSC-treated patients reported a significant decrease in knee pain and improved knee function, improved cartilage quality in defects on post-treatment MRI, and no adverse events [39]. Recently, Gupta et al. [40] examined the efficacy and safety of IA injection of allogeneic human BMSCs in knee OA. Sixty OA patients were randomized to receive $25 \times 10^{6}, 50 \times 10^{6}, 75 \times 10^{6}, 150 \times$ $10^{6}$ BMSCs or no BMSCs. The $25 \times 10^{6}$ BMSC dose was found to be most effective for reducing $\mathrm{OA}$ knee pain and there were no significant adverse events reported [40].

\section{Adipose-Derived MSCs}

In a phase I and II clinical trial, Jo et al. [41] investigated the efficacy and safety of IA injection of autologous human ASCs in patients with knee OA. Phase I consisted of $1 \times 10^{7}, 5 \times 10^{7}$, and $1 \times 10^{8}$ ASC-injected groups with 3 patients each and phase II included 9 patients receiving the high dose of $1 \times 10^{8}$ ASCs. The patients receiving $1 \times$ $10^{8}$ ASCs showed reduced OA knee pain, improved knee function, regeneration of articular cartilage defects with hyaline-like cartilage, and no serious adverse events [41]. Furthermore, in a two-centre phase I safety study of 18 consecutive patients with symptomatic and severe knee $\mathrm{OA}$, the European Union consortium Adipose-Derived Stromal Cells for Osteoarthritis (ADIPOA) has shown that IA injection of a single dose of $2 \times 10^{6}, 10 \times 10^{6}$, or $50 \times 10^{6}$ autologous ASCs to the knee was well tolerated, had no adverse effects, and resulted in an improvement in pain and functional outcome scores at 12 months [42].

\section{Systematic Reviews and Meta-Analyses of MSCs in $O A$}

In a meta-analysis of 11 clinical trials involving a total of 582 patients with knee OA, Yubo et al. [43] evaluated the clinical efficacy and safety of BMSC and ASC treatment for knee OA. The investigators demonstrated that MSC treatment improved pain and functional scores af- 
ter a 24-month follow-up compared to controls and were safe with no serious adverse events reported [43]. In a systematic review of 5 RCTs and 1 non-RCT on BMSCs and ASCs in knee OA, Pas et al. [44] reported that the 6 trials included for review showed high risk of bias and, in the absence of high-level evidence, the authors do not recommend MSC therapy in knee OA. Jevotovsky et al. [45] performed a systematic review on MSC therapy for OA with 61 studies identified, treating 2,390 patients with OA. BMSCs and ASCs were used in these included studies. The authors concluded an association between MSC therapy and improvement in pain and functional outcome scores, but stated the need for well-designed RCTs with reproducible cell preparation methods for BMSCs and ASCs and longer follow-up [45]. In summary, cell therapy with direct IA injection of MSCs should be considered a novel regenerative medicine strategy for knee OA. Direct IA injection of MSCs in the knee is safe, simple, does not require a surgical procedure, provides pain relief, improves function, and enhances cartilage quality. However, future RCTs and larger patient cohorts are required to demonstrate the safety and efficacy of MSCs in knee OA. Many studies suffer from a lack of high-level evidence and long-term follow-up. In addition, the diversity of cell preparation methods and lack of reproducibil- ity mean that many clinical trials do not contribute to a high-quality evidence base. Therefore, there is a compelling need for additional high-quality clinical data.

\section{Conclusion}

The delivery of MSCs to the osteoarthritic knee joint has emerged as a potential treatment option. Studies that are well designed with sufficient follow-up report positive outcomes. However, the scientific evidence in support of the efficacy of these treatments is limited and recommendations for clinical application remain variable and inconclusive. There are some global efforts to provide the clinical proof of concept in well-controlled, blinded, RCTs, and it will be necessary for high-quality clinical centres to lead this effort. The ultimate objective is to provide a cell therapy that is proven to be safe and effective, enhances repair and regenerates articular cartilage, and prevents or delays the onset of knee pain and OA.

\section{Disclosure Statement}

The authors have no disclosures.

\section{References}

1 Pelletier JP, Martel-Pelletier J, Abramson SB. Osteoarthritis, an inflammatory disease: potential implication for the selection of new therapeutic targets. Arthritis Rheum. 2001 Jun;44(6):1237-47.

2 Bijlsma JW, Berenbaum F, Lafeber FP. Osteoarthritis: an update with relevance for clinical practice. Lancet. 2011 Jun;377(9783):211526.

3 Caldwell B, Aldington S, Weatherall M, Shirtcliffe P, Beasley R. Risk of cardiovascular events and celecoxib: a systematic review and meta-analysis. J R Soc Med. 2006 Mar;99(3): $132-40$.

4 Evans CH, Kraus VB, Setton LA. Progress in intra-articular therapy. Nat Rev Rheumatol. 2014 Jan;10(1):11-22.

5 Campbell KA, Erickson BJ, Saltzman BM, Mascarenhas R, Bach BR Jr, Cole BJ, et al. Is local viscosupplementation injection clinically superior to other therapies in the treatment of osteoarthritis of the knee: a systematic review of overlapping meta-analyses. Arthroscopy. 2015 Oct;31(10):2036-45.e14.
6 Campbell KA, Saltzman BM, Mascarenhas R, Khair MM, Verma NN, Bach BR Jr, et al. Does intra-articular platelet-rich plasma injection provide clinically superior outcomes compared with other therapies in the treatment of knee osteoarthritis? a systematic review of overlapping meta-analyses. Arthroscopy. 2015 Nov;31(11):2213-21.

7 Jevsevar DS, Shores PB, Mullen K, Schulte DM, Brown GA, Cummins DS. Mixed treatment comparisons for nonsurgical treatment of knee osteoarthritis: a network meta-analysis. J Am Acad Orthop Surg. 2018 May;26(9): 325-36.

8 Goodman SB, Konttinen YT, Takagi M. Joint replacement surgery and the innate immune system. J Long Term Eff Med Implants. 2014; 24(4):253-7.

9 Khan M, Osman K, Green G, Haddad FS. The epidemiology of failure in total knee arthroplasty: avoiding your next revision. Bone Joint J. 2016 Jan;98-B(1 Suppl A):105-12.

10 Sadoghi P, Liebensteiner M, Agreiter M, Leithner A, Böhler N, Labek G. Revision surgery after total joint arthroplasty: a complication-based analysis using worldwide arthroplasty registers. J Arthroplasty. 2013 Sep; 28(8):1329-32.
11 National Joint Registry for England and Wales [Internet]. 1st Annual Report, 2004 [cited 2018 Dec 15]. Available from: http:// www.njrcentre.org.uk/njrcentre/Portals/0/ Documents/England/Reports/NJR_AR_1. pdf.

12 Swedish Knee Arthroplasty Register [Internet]. Annual report, 1999 [cited 2018 Dec 15]. Available from: http://www.myknee.se/ pdf/97_report1999.pdf.

13 Australian Orthopaedic Association [Internet]. National Joint Replacement Registry, 1st Annual Report, 2000 [cited 2018 Dec 15]. Available from: https://aoanjrr.sahmri.com/ documents/10180/75186/Annual\%20Rep or t \% 202000 ? version $=1.0$ $\& \mathrm{t}=1349407109407$.

14 Kurtz S, Ong K, Lau E, Mowat F, Halpern M. Projections of primary and revision hip and knee arthroplasty in the United States from 2005 to 2030. J Bone Joint Surg Am. 2007 Apr; 89(4):780-5.

15 ter Huurne M, Schelbergen R, Blattes R, Blom A, de Munter W, Grevers LC, et al. Antiinflammatory and chondroprotective effects of intraarticular injection of adipose-derived stem cells in experimental osteoarthritis. Arthritis Rheum. 2012 Nov;64(11):3604-13. 
16 Desando G, Cavallo C, Sartoni F, Martini L, Parrilli A, Veronesi F, et al. Intra-articular delivery of adipose derived stromal cells attenuates osteoarthritis progression in an experimental rabbit model. Arthritis Res Ther. 2013 Jan;15(1):R22.

17 Diekman BO, Wu CL, Louer CR, Furman BD, Huebner JL, Kraus VB, et al. Intra-articular delivery of purified mesenchymal stem cells from C57BL/6 or MRL/MpJ superhealer mice prevents posttraumatic arthritis. Cell Transplant. 2013;22(8):1395-408.

18 Lawrence RC, Felson DT, Helmick CG, Arnold LM, Choi H, Deyo RA, et al.; National Arthritis Data Workgroup. Estimates of the prevalence of arthritis and other rheumatic conditions in the United States. Part II. Arthritis Rheum. 2008 Jan;58(1):26-35.

19 Murphy L, Schwartz TA, Helmick CG, Renner JB, Tudor G, Koch G, et al. Lifetime risk of symptomatic knee osteoarthritis. Arthritis Rheum. 2008 Sep;59(9):1207-13.

20 Lawrence JS, Bremner JM, Bier F. Osteo-arthrosis. Prevalence in the population and relationship between symptoms and $\mathrm{x}$-ray changes. Ann Rheum Dis. 1966 Jan;25(1):124.

21 Felson DT. Risk factors for osteoarthritis: understanding joint vulnerability. Clin Orthop Relat Res. 2004 Oct;427 Suppl:S16-21.

22 McAlindon TE, Felson DT, Zhang Y, Hannan MT, Aliabadi P, Weissman B, et al. Relation of dietary intake and serum levels of vitamin D to progression of osteoarthritis of the knee among participants in the Framingham Study. Ann Intern Med. 1996 Sep;125(5): 353-9.

23 Henrotin YE, Bruckner P, Pujol JP. The role of reactive oxygen species in homeostasis and degradation of cartilage. Osteoarthritis Cartilage. 2003 Oct;11(10):747-55.

24 Slemenda C, Brandt KD, Heilman DK, Mazzuca S, Braunstein EM, Katz BP, et al. Quadriceps weakness and osteoarthritis of the knee. Ann Intern Med. 1997 Jul;127(2):97104.

25 Pai YC, Rymer WZ, Chang RW, Sharma L. Effect of age and osteoarthritis on knee proprioception. Arthritis Rheum. 1997 Dec; 40(12):2260-5.
26 Englund M, Guermazi A, Roemer FW, Aliabadi P, Yang M, Lewis CE, et al. Meniscal tear in knees without surgery and the development of radiographic osteoarthritis among middle-aged and elderly persons: The Multicenter Osteoarthritis Study. Arthritis Rheum. 2009 Mar;60(3):831-9.

27 Hill CL, Seo GS, Gale D, Totterman S, Gale ME, Felson DT. Cruciate ligament integrity in osteoarthritis of the knee. Arthritis Rheum. 2005 Mar;52(3):794-9.

28 Hudelmaier M, Glaser C, Hohe J, Englmeier KH, Reiser M, Putz R, et al. Age-related changes in the morphology and deformational behavior of knee joint cartilage. Arthritis Rheum. 2001 Nov;44(11):2556-61.

29 Burr DB. The importance of subchondral bone in the progression of osteoarthritis. J Rheumatol Suppl. 2004 Apr;70:77-80.

30 Rosenthal AK. Calcium crystal deposition and osteoarthritis. Rheum Dis Clin North Am. 2006 May;32(2):401-12.

31 Hass R, Kasper C, Böhm S, Jacobs R. Different populations and sources of human mesenchymal stem cells (MSC): a comparison of adult and neonatal tissue-derived MSC. Cell Commun Signal. 2011 May;9(1):12.

32 Dominici M, Le Blanc K, Mueller I, SlaperCortenbach I, Marini F, Krause D, et al. Minimal criteria for defining multipotent mesenchymal stromal cells. The International Society for Cellular Therapy position statement. Cytotherapy. 2006;8(4):315-7.

33 Singer NG, Caplan AI. Mesenchymal stem cells: mechanisms of inflammation. Annu Rev Pathol. 2011;6(1):457-78.

34 Cianca JC, Jayaram P. Musculoskeletal injuries and regenerative medicine in the elderly patient. Phys Med Rehabil Clin N Am. 2017 Nov;28(4):777-94.

35 De Ugarte DA, Morizono K, Elbarbary A, Alfonso Z, Zuk PA, Zhu M, et al. Comparison of multi-lineage cells from human adipose tissue and bone marrow. Cells Tissues Organs. 2003; 174(3):101-9.

36 Al-Nbaheen M, Vishnubalaji R, Ali D, Bouslimi A, Al-Jassir F, Megges M, et al. Human stromal (mesenchymal) stem cells from bone marrow, adipose tissue and skin exhibit differences in molecular phenotype and differentiation potential. Stem Cell Rev. 2013 Feb; 9(1):32-43.
37 Orozco L, Munar A, Soler R, Alberca M, Soler F, Huguet M, et al. Treatment of knee osteoarthritis with autologous mesenchymal stem cells: a pilot study. Transplantation. 2013 Jun; 95(12):1535-41.

38 Vangsness CT Jr, Farr J 2nd, Boyd J, Dellaero DT, Mills CR, LeRoux-Williams M. Adult human mesenchymal stem cells delivered via intra-articular injection to the knee following partial medial meniscectomy: a randomized, double-blind, controlled study. J Bone Joint Surg Am. 2014 Jan;96(2):90-8.

39 Vega A, Martín-Ferrero MA, Del Canto F, Alberca M, García V, Munar A, et al. Treatment of knee osteoarthritis with allogeneic bone marrow mesenchymal stem cells: a randomized controlled trial. Transplantation. 2015 Aug;99(8):1681-90.

40 Gupta PK, Chullikana A, Rengasamy M, Shetty N, Pandey V, Agarwal V, et al. Efficacy and safety of adult human bone marrow-derived, cultured, pooled, allogeneic mesenchymal stromal cells (Stempeucel ${ }^{\circledR}$ ): preclinical and clinical trial in osteoarthritis of the knee joint. Arthritis Res Ther. 2016 Dec;18(1):301.

41 Jo CH, Lee YG, Shin WH, Kim H, Chai JW, Jeong EC, et al. Intra-articular injection of mesenchymal stem cells for the treatment of osteoarthritis of the knee: a proof-of-concept clinical trial. Stem Cells. 2014 May;32(5): 1254-66.

42 Pers YM, Rackwitz L, Ferreira R, Pullig O, Delfour C, Barry F, et al.; ADIPOA Consortium. Adipose mesenchymal stromal cellbased therapy for severe osteoarthritis of the knee: a phase I dose-escalation trial. Stem Cells Transl Med. 2016 Jul;5(7):847-56.

43 Yubo M, Yanyan L, Li L, Tao S, Bo L, Lin C. Clinical efficacy and safety of mesenchymal stem cell transplantation for osteoarthritis treatment: A meta-analysis. PLoS One. 2017 Apr;12(4):e0175449.

44 Pas HI, Winters M, Haisma HJ, Koenis MJ, Tol JL, Moen MH. Stem cell injections in knee osteoarthritis: a systematic review of the literature. Br J Sports Med. 2017 Aug;51(15): 1125-33.

45 Jevotovsky DS, Alfonso AR, Einhorn TA, Chiu ES. Osteoarthritis and stem cell therapy in humans: a systematic review. Osteoarthritis Cartilage. 2018 Jun;26(6):711-29. 